\title{
Relationship between knowledge of green product, social impact and perceived value with green purchase behavior
}

\author{
Alprida Harahap ${ }^{1, *}$, Aminah Zuhriyah ${ }^{1}$, Henita Rahmayanti ${ }^{1}$, and Nadiroh ${ }^{1}$ \\ ${ }^{1}$ Population and Environmental Education, State University of Jakarta, 13220, Rawamangun, \\ Indonesia
}

\begin{abstract}
Concern for the environment causes an increase in consumer demand for environmentally friendly products. The purpose of this study was to look at the relationship between knowledge about green products, social impact and perception value with green buying behavior. This research is a quantitative and observational type research with cross sectional approach conducted on junior high school students in Jakarta. The results show that there is a relationship between knowledge about the product and green buying behavior, namely p $(0.02)<0.05$ while the knowledge of purchasing and using does not have a relationship with the green buying behavior. The indicator of family influence also shows a relationship with green buying behavior, namely $\mathrm{p}(0.04)<0.05$ while the influence of friends and social status does not have a relationship with green buying behavior. And the indicator of functional value and selfexperimentation have a relationship with green buying behavior while emotional values are not seen to have a relationship with green buying behavior. Therefore, from this research can be done approaches to indicators that have a relationship to invite someone in green buying behavior.
\end{abstract}

\section{Introduction}

Globally unsustainable levels of consumption lead to severe environmental sustainability issues such as global warming, water, air and soil pollution, and waste that encourage people to change their conventional consumption patterns and purchasing behavior in pursuit of environmental sustainability [1] In this case there is an environmental concern for consumers that causes an increase in consumer demand for environmentally friendly products [2]. The exposure to environmental damage as mentioned above, one of which is human action and this cannot be seen by consumers [3]. Environmental damage has become a major problem because the environment continues to be used for human prosperity without adhering to the principle of sustainability.

With so many feelings or organizations committed to green marketing. This Green initiative has resulted in the development of green products in various industries including

\footnotetext{
${ }^{*}$ Corresponding author: liaalprida12@gmail.com
} 
food, construction, energy, automobiles, agriculture, consumer goods, food, tourism, etc. Providing green products is an advantage for entrepreneurs The main requirements for green products (food organic or bio, environmentally friendly, cosmetics, etc.) is that raw materials must be environmentally friendly, grow without pesticides and chemical fertilizers, without toxic materials; the use of genetically modified organisms is also limited, the package must be environmentally friendly as well [4] Environmental knowledge has often been assumed to be the main motivator of green consumer behavior [5] Consumers who are more knowledgeable about issues related to the environment and the benefits of using green products may have a more positive attitude on these products [6] However, green products may be more expensive than other comparative products but have lower life cycle costs, because products can be recycled easily causing a slight negative impact on the environment [7].

Likewise, social impact is very influential for the formation and development of attitudes to lead to green buying behavior, because the level of influence of family, friends and social status [8] has a very strong influence on a person. This is supported by research conducted by Hojat et.al [9] that social impacts do not cause the willingness to buy green products among Iranian women. Therefore, it is necessary to have an appropriate strategy so that there is value felt from green products with consideration for the environment. In a study conducted said that values play an important role in the process of consumer purchasing decisions, the green values that are perceived positively are related to the intention to purchase green products and are environmentally friendly [10]. Green purchasing behavior in this study is the consumption of environmentally friendly products that can contribute to minimizing environmental impacts. Therefore, this study wants to see the relationship between knowledge about green products, social impact and the value of perceptions about green buying behavior towards students who receive environmental education subjects.

\section{Method}

This research was conducted with quantitative methods. Data were obtained quantitatively through questionnaire. The survey data was conducted by collecting 100 students participated as subjects from one junior high school in Jakarta, Indonesia. Students were chosen with purposive sampling with the requirement of students who had received material about the environment, and were willing to be included in the sample. Before performing the analysis, data were collected for validation and reliability of the questionnaire. Questionnaires that have been proven valid and reliable were then used as a variable measurement tool.

Variabels consist of dependent variables namely green buying behavior and independent variables, namely product knowledge, social impact and perceived value. Descriptive factors are used in data presentation, central size and size of spread. Data presentation is a distribution list and histogram. Central sizes are mean, median, and mode. The size of the spread is the standard variance and deviation. Inferential analysis is used to test the hypothesis using regression analysis and correlation which is preceded by the requirements analysis of the regression analysis, namely the normality test and linearity test.

\section{Discussion}

\subsection{Knowledge of green product}


Knowledge of green products, namely indicators of product knowledge, usage knowledge and purchasing knowledge. Where the final results of the measurement of knowledge about green products are as obtained by an average of the knowledge of products from 100 samples, namely 3.12, and knowledge of the use of 100 samples, namely, 2.35 and knowledge of purchases from 100 samples, namely 2.38 , where the middle value is average flat on product knowledge is 3.0, while usage and purchase knowledge is 2.0. In the knowledge of the product that often appears is 3.0, while the knowledge of usage and purchase is the same, which is 2.0. Variance in product knowledge is 0.612 and usage knowledge is 0.432 while purchase knowledge is 0.734 . The standard deviation shows that there is 0.78 of product knowledge and 0.66 of usage knowledge and purchase knowledge of 0.74 .

Then the sample with an average value on product knowledge $(3.12+0.78)=4$ to value $(3.12$ to 0.78$)=3$, and to the knowledge of usage $(2.35+0.66)=3$ to the value $(2.35-0.66)$ $=2$, while the knowledge of the purchase challenge is $(2.38+0.74)=3$ to the value $(2.38$ $0.66)=1$.

Table 1. Multiple linear regression result against knowledge variable about green product.

\begin{tabular}{|c|c|c|c|}
\hline Indicator & $\mathrm{B}$ & Beta & p-value \\
\hline $\begin{array}{c}\text { Knowledge } \\
\text { about product }\end{array}$ & -0.385 & 0.320 & 0.02 \\
\hline $\begin{array}{c}\text { Knowledge } \\
\text { about usage }\end{array}$ & -0.121 & -0.084 & 0.393 \\
\hline $\begin{array}{c}\text { Knowledge } \\
\text { about } \\
\text { purchases }\end{array}$ & -0.158 & -0.123 & 0.226 \\
\hline
\end{tabular}

In the table above shows that there is a relationship between knowledge about products with green buying behavior with $\mathrm{Q}$ (alpha) $=0.05$. While in the knowledge of use and purchase there is no relationship, namely $\mathrm{p}(0.02)>0.05$.

\subsection{Social impact}

Based on the result are as obtained by the average effect of friends from 100 samples, namely 2.38, and the influence of families from 100 samples, namely, 3.2 and the influence of social status of 100 samples, namely 4.64, where the mean middle value on the influence of friends is 2.0, and family influence is 3.0 while the influence of social status is 5.0. In the influence of friends that often appear is 2.0 , and family influence is 3.0 and the influence of social status, which is 2.0. Variance in the influence of friends is 1.09 and family influence is 0.61 while the influence of social status is 27.1. The standard deviation shows that the influence of friends is 1.05 and family influence is 1.05 and the influence of social status is 5.20 .

In the table following shows that there is a relationship between family influence with green buying behavior with $\mathrm{Q}$ (alpha) $=0.05$, that is $\mathrm{p}(0.004)<0.05$. While the influence of friends and social status does not have a relationship. 
Table 2. Multiple linear regression result against variable impact social.

\begin{tabular}{|c|c|c|c|}
\hline Indicator & $\mathrm{B}$ & Beta & $\mathrm{p}$-value \\
\hline $\begin{array}{c}\text { Impact of } \\
\text { friend }\end{array}$ & 0.055 & -0.061 & 0.540 \\
\hline $\begin{array}{c}\text { Impact of } \\
\text { family }\end{array}$ & 0.350 & 0.291 & 0.004 \\
\hline $\begin{array}{c}\text { Impact of } \\
\text { status social }\end{array}$ & 0.012 & 0.067 & 0.496 \\
\hline
\end{tabular}

\subsection{Perception value}

Based on the result are obtainrd by the average the functional value of 100 samples is 2.57 , and the emotional value of 100 samples is 3.05 and the self-expression value of 100 samples is 3.2, where the mean middle value on perception value is 3,0 based on its dimensions. Based on its dimensions, the perception value that often arises is 3.0. Variance in the functional value is 0.87 and emotional value is 1.28 while the value of selfexpression is 0.734 . The standard deviation shows that the knowledge of the product is 0.78 and the knowledge of usage is 0.66 and the knowledge about the purchase is 0.74 .

Table 3. Multiple linear regression result against variable perception values.

\begin{tabular}{|c|c|c|c|}
\hline Indicator & $\mathrm{B}$ & Beta & $\mathrm{p}$-value \\
\hline $\begin{array}{c}\text { Fungsional } \\
\text { value }\end{array}$ & -0.230 & -0.229 & 0.024 \\
\hline $\begin{array}{c}\text { Emotional } \\
\text { value }\end{array}$ & 0.149 & 0.179 & 0.061 \\
\hline $\begin{array}{c}\text { Self-expression } \\
\text { value }\end{array}$ & 0.404 & 0.336 & 0.001 \\
\hline
\end{tabular}

In the table above shows that there is a relationship between the value of self-expression with green buying behavior with $\mathrm{Q}$ (alpha) $=0.05$, namely $\mathrm{p}(0.001)<0.05$. While the functional and emotional values do not have a relationship.

Environmental knowledge has often been assumed to be the main motivator of green consumer behavior [11]. Consumers interpret and assess a product with the amount of information stored in their memories [12]. Environmental information guides consumers in choosing products that are more friendly to confusion [13]. In the study Paraschos Maniatis [14] mentions 15 indicators of consumers in deciding to buy green products, one of which is knowledge about the product. Green products evolve as a result of increasing concerns about global and local levels of pollution, global warming, reduced natural reserves, and abundant waste [15]. The green concept is extended to almost every step of the process of procuring raw materials, production, storage, packaging, shipping and distribution [16]. 
Green products have been shown to reduce harmful side effects, reduce hazards, reduce toxic substances, reduce health problems, increase recycling, and improve environmental friendliness [17].

In this study, knowledge of green products with indicators of knowledge about the product itself, knowledge of its use and knowledge of purchases. Where in the results of the analysis there is a relationship between knowledge about products and green buying behavior, while knowledge about use and purchase has no relationship with green buying behavior. The purpose of the knowledge about the product, seen from how much the respondents know and understand about the environmental impact when buying and using the product they buy.

According to Hojjat, M and Behnaz K [9] social impacts are the level of influence of families and relatives, such as parents, relatives and close friends and friends on the behavior and decisions of each individual. So, if you can turn this influence into strength, the behavior of people or groups can be changed. Social impacts can be included in marketing green products through social ties. Consumers, who care about the environment, buy products and services that have a positive impact on the environment. People, who are concerned about the environment, take actions such as spending more to protect the environment, prefer green products for other products, use of public transport to protect the environment, separation and delivery of recyclable waste, save energy and refuse to buy standard sprays and buy drinks in an eco-label container.

In this study social impact has three indicators, namely, the influence of friends, family influence and the influence of social status. This, which has a relationship with green purchasing behavior is the dimension of family influence. It is assumed that the family is the closest and closest place to the respondent. This research is in line with Hojjat, $\mathrm{M}$ and Behnaz K [9] stating that social impacts have a positive relationship with the purchase of green products and also supported by Abbasi, Enayati and Rahbar [18].

Value is defined as what is felt to assess the overall use of a product based on consumer perception, Zeithmal (1988) [19], where value perception is theoretical and empirical support for Inklus. In general, green products are more expensive than not and consumers will not compromise on the excellent function of traditional products [10]. Perception value about green buying behavior, that is, is interpreted as how the respondent's perception when choosing a product. In this study perception values have three indicators, namely, functional value, emotional value and the value of self-expression in buying green products.

In this study the perception value that has a relationship with green buying behavior is the functional value and self-expression. This is in line with the research conducted by Rambalak, Y and Govind S. P [20] namely that there is a relationship between perception values such as product values that are perceived to function with green purchase intentions.

\section{Conclusion}

A lot of green purchasing behavior research has been done both nationally and internationally. However, this study contributes about product knowledge which is divided into three dimensions, namely knowledge in products, purchasing, and usage, in this case, knowledge of products greatly contributes to green purchasing behavior. Likewise, social impacts such as family influence have a relationship with green buying behavior so that when promoting a green product can approach the family. In addition, the value of perception is also a very influential factor in green purchasing behavior, such as selfexpression. Limitations in this study are not conducting interviews to obtain reasons for the respondents' green buying behavior. 


\section{Acknowledgements}

We are grateful for the support given by students who are willing to be respondents in this study and also to Mr. Damianus Dai Koban has provided support

\section{References}

1. J. Deepak, K. Rishi, Journal of Retailing and Consumer Services, 41, 60-69 (2018)

2. K. Maturos, et al., Journal of Cleaner Production, 66, 528-536 (2014)

3. C. Tobler, Green consumer behavior consumers' knowledge and willingness to act proenvironmentally" (University of Zurich, 2011)

4. L. Genovaite, M. Justina, B. Jurg, Kaunas, Lithuania 125, 38-46 (2016)

5. K. Peattie, P. Charls, Qualitative Market Research: An International Journal, 4, 8, 357 $370(2011)$

6. H.K. Bang, et al., Psychol. Mark. 17, 6, 449-468 (2000)

7. M. Paraschos, Journal of Cleaner Production, 1-14 (2015)

8. K. Lee, Marketing Intelligence \& Planning, 26, 6, 573-586 (2008)

9. M. Hojjat, K. Behnaz, Iran 36, 441-447 (2016)

10. Y.S. Chen, C.H. Chang, Manag. Decis. 50, 3, 502-520 (2012)

11. H. Zhao, et al., J. Clean. Prod. 63, 143-151 (2014)

12. B.C. Tan, Int. J. Bus. Manag. 6, 12, 14-27 (2011)

13. A. Gilg, S. Barr, N. Ford, Futures 37, 481-504 (2015)

14. M. Paraschos, Journal of Cleaner Production, 1-14 (2015)

15. S.K. Srivastava, Int. J. Manag. Rev. 9, 1, 53-80 (2017)

16. R. Palevich, The Lean Sustainable Supply Chain: How to Create a Green Infrastructure with Lean Technologies (Pearson Education, London, 2012)

17. S.G. Azevedo, Transp. Res. Part E 47, 850-871 (2011)

18. J. Abbassi, et al., Investigating The factors Affecting Iranian Students' Green Buying Behavior (2012)

19. V.A. Zeithaml, J. Mark. 52, 3, 2-22 (1988)

20. Y. Rambalak, S.P. Govind, India 134, 114-122 (2017) 